\title{
DESIGN AND IN VITRO CHARACTERIZATION OF FLUTRIMAZOLE MICROSPHERES LOADED TOPICAL EMULGEL
}

\section{MUTHADI RADHIKA REDDY ${ }^{1 *}$, SOUMYASTUTIPATNAIK ${ }^{2}$}

Department of School of Pharmacy, Guru Nanak Institutions Technical Campus, Hyderabad, Telangana, India. Email: muthadiradhika@gmail.com

Received: 28 May 2019, Revised and Accepted: 26 July 2019

\section{ABSTRACT}

Objective: Flutrimazole is a topical antifungal agent which displays potent broad spectrum in vitro activity against dermatophytes, filamentous fungi, and yeasts. The purpose of the present study is to formulate and evaluate microspheres loaded topical gel containing flutrimazole as model drug microspheres were prepared using aqueous ionotropic gelation method.

Methods: Different polymers, the different drug to polymer(s) ratio(s) and other parameters were screened to study their effects on the properties of microspheres and to optimize each parameter. The controlled release emulgel was formulated by changing the polymer ratio. Fourier transform infrared study confirmed the purity of the drug, concede no interaction between the drug and excipients and analyze the parameters affecting the morphology and other characteristics of the resultant products employing scanning electron microscopy

Results: Microspheres loaded topical gel has been shown that encapsulation and controlled release of flutrimazole could reduce the side effect while also reducing percutaneous absorption when administered to the skin. The microspheres obtained were subjected to the preformulation studies such as bulk density, tapped density, angle of repose, Carr's index, and Hausner's ratio the results obtained were within the limit. The microspheres were characterized by percentage yield, drug entrapment efficiency, and particle size analysis, then the optimized microspheres formulation were incorporated into the gel prepared with various polymer(s) ratio(s) and were evaluated by parameters such as visual inspection, $\mathrm{pH}$ measurement, spreadability studies, viscosity, and in vitro drug release using Franz diffusion cell.

Conclusion: The result of studies revealed that the optimized batch shows $97.24 \%$ release in $12 \mathrm{~h}$ and stable for around there. The microsphere loaded gel has advantages such as efficient absorption and more drug retention time.

Keywords: Flutrimazole, Microsphere loaded topical gel, Controlled release, Fourier transform infrared.

(c) 2019 The Authors. Published by Innovare Academic Sciences Pvt Ltd. This is an open access article under the CC BY license (http://creativecommons. org/licenses/by/4. 0/) DOI: http://dx.doi.org/10.22159/ajpcr.2019.v12i9.34341

\section{INTRODUCTION}

For many decenniums, medication of an acute disease or a chronic disease has been accomplished by delivering drugs to the patients through various pharmaceutical dosage forms such as tablets, capsules, pills, creams, ointments, liquids, aerosols, injectables, and suppositories as carriers. This results in a fluctuated drug level and consequently undesirable toxicity and poor efficiency. This factor as well as other factors such as repetitive dosing and unpredictable absorption leads to the concept of controlled drug delivery systems [1-3]. The objective of controlled release drug delivery includes two important aspects, namely, spatial placement and temporal delivery of the drug. Spatial placement relates to targeting a drug to a specific organ or tissue, while temporal delivery refers to controlling the rate of drug delivery to the target tissue [4]. Oral controlled release dosage forms have been developed over the past three decades due to their considerable therapeutic advantages such as ease of administration, patient compliance, and flexibility in formulation. However, this approach is being filled with several physiological difficulties such as inability to restrain and locate the controlled drug delivery system within the desired region of the gastrointestinal tract due to variable motility and relatively brief gastric emptying time in humans which normally averages $2-3 \mathrm{~h}$ through the major absorption zone, i.e. stomach and upper part of the intestine can result in incomplete drug release from the drug delivery system leading to reduced efficacy of the administered dose [5]. Microspheres can be defined as solid, approximately spherical particles ranging in size from 1 to $1000 \mu \mathrm{m}$. They are made of polymeric, waxy, or other protective materials, that is, biodegradable synthetic polymers and modified natural products such as starches, gums, proteins, fats, and waxes. The natural polymers include albumin and gelatin. The synthetic polymers include polylactic acid and polyglycolic acid. There are two types of microspheres: microcapsules, where the entrapped substance is completely surrounded by a distinct capsule wall, and micro matrices, where the entrapped substance is dispersed throughout the microsphere matrix. Microspheres are small and have a large surface to volume ratios. At the lower end of their size range, they have colloidal properties [6].

Flutrimazole 1-[(2-fluorophenyl)(4-fluorophenyl)phenylmethyl]$1 \mathrm{H}$-imidazole is a drastic antifungal drug of the imidazole azole family with low aqueous solubility $\left(0.71 \mathrm{mg} \mathrm{m}^{-1}\right)$, which classifies it to biopharmaceutics classification system Class II. Flutrimazole is mainly used for the treatment of several fungi infections, such as invasive superficial mycosis infections $[7,8]$. Its limited solubility in water classified flutrimazole as a drug with low bioavailability, which limits its effectiveness. This major problem can be solved only by new clinical trends and new pharmaceutical formulations. The objective of work was envisaged to reduce the dosing frequency and improves patient compliance by designing and evaluating the controlled release of flutrimazole microspheres loaded gel for mycosis infection. The microsphere loaded gel has advantages such as efficient absorption and more drug retention time.

\section{MATERIALS AND METHODS}

\section{Materials}

Flutrimazole was received as a gift sample from Pfizer, Hyderabad, India, which is a water-insoluble drug, was chosen as a model drug. EC 
(Signet Chemical Corporation, Mumbai, India) was used as a matrixforming agent, and hydroxypropyl methylcellulose (HPMC) various grades (Merck Specialities Pvt. Ltd., Mumbai, India) were used as polymers in this study. Distilled water was used for all experiments. All other chemicals were of analytical pharmaceutical grade.

\section{Methods}

Drug-excipient compatibility studies [5]

Fourier transform infrared (FT-IR) spectroscopy

FT-IR techniques have been used to study the physical and chemical interaction between drug and excipients used. The physical properties of the physical mixture were compared with those of plain drug. Samples were mixed thoroughly with $100 \mathrm{mg}$ potassium bromide IR powder and compacted under vacuum at a pressure of about 12 psi for 3 min. The resultant disc was mounted in a suitable holder in Perkin Elmer IR spectrophotometer and the IR spectrum was recorded from $3500 \mathrm{~cm}$ to $500 \mathrm{~cm}$. The resultant spectrum was compared for any spectrum changes and data reported in Table 2.

Preparation of standard calibration curve of flutrimazole $10 \mathrm{mg}$ of flutrimazole drug was accurately weighed and dissolved in $10 \mathrm{ml}$ of $6.8 \mathrm{pH}$ in $10 \mathrm{ml}$ volumetric flask, to make $(1000 \mu \mathrm{g} / \mathrm{ml})$ standard stock solution (1). Then, $1 \mathrm{ml}$ stock solution (1) was taken in another $10 \mathrm{ml}$ volumetric flask to make $(100 \mu \mathrm{g} / \mathrm{ml})$ standard stock solution (2), then again $1 \mathrm{ml}$ of stock solution (2) was taken in another $10 \mathrm{ml}$ volumetric flask, and then final concentrations were prepared 2, $4,6,8,10,12,14,16,18$, and $20 \mu \mathrm{g} / \mathrm{ml}$ with $6.8 \mathrm{pH}$. The absorbance of the standard solution was determined using ultraviolet (UV)/ Visible spectrophotometer at $270 \mathrm{~nm}$. The linearity of the standard curve was assessed from the square of correlation coefficient $\left(\mathrm{r}^{2}\right)$ which determined by least-squares linear regression analysis. The absorbance so obtained is tabulated in Table 3. The calibration curve was constructed, as shown in Fig. 2.

Preparation of microspheres

Batches of microspheres were prepared which involved reaction using ethyl cellulose and HPMC as polymers and the mucoadhesive polymer were dispersed in purified water $(10 \mathrm{ml})$ to form a homogeneous polymer mixture. The API, flutrimazole $(100 \mathrm{mg})$ was added to the polymer premix and mixed thoroughly with a stirrer to form a viscous dispersion. The resulting dispersion was then added through a $22 \mathrm{G}$ needle into calcium chloride $(4 \% \mathrm{w} / \mathrm{v})$ solution. The addition was done with continuous stirring at $200 \mathrm{rpm}$. The added droplets were retained in the calcium chloride solution for $30 \mathrm{~min}$ to complete the curing reaction and to produce rigid spherical microspheres. The microspheres were collected by decantation, and the product thus separated was washed repeatedly with purified water to remove excess calcium impurity deposited on the surface of microspheres and then air-dried. The composition of all the formulations is shown in Table 1.

\section{Characterization of microspheres [6]}

Percentage yield

The percentage of production yield was calculated from the weight of dried microspheres recovered from each batch and the sum of the initial weight of starting materials. The percentage yield was calculated using the following formula:

$\%$ Yield $=$ Practical mass (Microspheres) $/$ Theoretical mass (Polymer+Drug) $\times 100$

Drug entrapment efficiency

Powdered microspheres were suspended in $10 \mathrm{ml}$ of phosphate buffer ( $\mathrm{pH}$ 6.8). After $24 \mathrm{~h}$, the solution was filtered, the filtrate was centrifuged at $2000 \mathrm{rpm}$ for $3 \mathrm{~min}$, and then analyzed for drug content spectrophotometrically (Shimadzu UV-1800, Japan)) at $272 \mathrm{~nm}$, and the concentration of soluble drug was calculated [9]. The amount of drug entrapped in the microspheres was calculated by the following formula,

Entrapment efficiency during $=$ Weight of drug added formulation - weight of drug recovered from

Microspheres/Weight of drug added during formulation

\section{Particle size analysis}

Samples of the microparticles were analyzed for particle size by optical microscope. The instrument was calibrated and found that 1 unit of eyepiece micrometer was equal to $12.5 \mu \mathrm{m}$. Nearly about 100 microparticles sizes were calculated under $\times 45$ magnification.

The average particle size was determined using the Edmondson's equation:

$\mathrm{D}_{\text {mean }}=\frac{\mathrm{nd}}{\mathrm{n}}$

Where,

$\mathrm{n}$ - Number of microspheres observed

$\mathrm{d}$ - Mean size range

Table 1: Formulation of bioadhesive microspheres

\begin{tabular}{|c|c|c|c|c|c|c|c|c|c|c|}
\hline S. No. & Ingredients & F1 & F2 & F3 & F4 & F5 & F6 & F7 & F8 & F9 \\
\hline 1. & Drug & 100 & 100 & 100 & 100 & 100 & 100 & 100 & 100 & 100 \\
\hline 2. & HPMCK4M & 100 & 200 & 300 & & & & & & \\
\hline 3. & HPMCK15M & & & & 100 & 200 & 300 & & & \\
\hline 4. & HPMCKK100M & & & & & & & 100 & 200 & 300 \\
\hline 5. & Methanol & 5 & 5 & 5 & 5 & 5 & 5 & 5 & 5 & 5 \\
\hline 6. & Water & 10 & 10 & 10 & 10 & 10 & 10 & 10 & 10 & 10 \\
\hline 7. & Calcium chloride (5\%) & QS & QS & QS & QS & QS & QS & QS & QS & QS \\
\hline
\end{tabular}

Table 2: Preparation of emulgel formulations

\begin{tabular}{|c|c|c|c|c|c|c|c|c|c|c|}
\hline S. No. & Ingredients & F1 & F2 & F3 & F4 & F5 & F6 & F7 & F8 & F9 \\
\hline 1. & Carbopol 940 (mg) & 100 & 200 & 300 & - & - & - & - & - & - \\
\hline 2. & Carbopol 934 (mg) & - & - & - & 100 & 200 & 300 & - & - & - \\
\hline 3. & Carbopol 974 (mg) & - & - & - & - & - & - & 100 & 200 & 300 \\
\hline 4. & Triethanolamine $(\mathrm{v} / \mathrm{v})$ & $2 \%$ & $2 \%$ & $2 \%$ & $2 \%$ & $2 \%$ & $2 \%$ & $2 \%$ & $2 \%$ & $2 \%$ \\
\hline 5. & PEG $(\% \mathrm{~V} / \mathrm{W})$ & $30 \%$ & $30 \%$ & $30 \%$ & $30 \%$ & $30 \%$ & $30 \%$ & $30 \%$ & $30 \%$ & $30 \%$ \\
\hline 6. & Methylparaben (mg) & 750 & 750 & 750 & 750 & 750 & 750 & 750 & 750 & 750 \\
\hline 7. & Distilled waters (ml) & QS & QS & QS & QS & QS & QS & QS & QS & QS \\
\hline
\end{tabular}


Micromeritic properties [6]

Bulk density, tapped density, Hausner's ratio, and Carr's index were determined to assess the flowability of the prepared microspheres.

Bulk density

The product was tapped using bulk density apparatus for 1000 taps in a cylinder, and the change in volume was measured. Bulk density of the formulations was determined using the following formula:

Bulk Density $=$ Total Weight $/$ Total bulk Volume

Table 3: Calibration curve data for flutrimazole in simulated fluid pH 6.8 buffer at $261 \mathrm{~nm}$

\begin{tabular}{ll}
\hline Concentration $(\boldsymbol{\mu g} / \mathbf{1} \mathbf{~ m l})$ & Abs \\
\hline 0.5 & 0.155 \\
1 & 0.301 \\
1.5 & 0.441 \\
2 & 0.621 \\
2.5 & 0.744 \\
3 & 0.971 \\
\hline
\end{tabular}

Table 4: Peak results for Fourier transform infrared spectroscopy studies of flutrimazole with the excipient

\begin{tabular}{|c|c|c|c|}
\hline S. No. & Functional groups & Present peaks & $\begin{array}{l}\text { Actual } \\
\text { frequency range }\end{array}$ \\
\hline 1. & $\begin{array}{l}\mathrm{C}=\mathrm{N} \\
\text { stretching (aromatic) }\end{array}$ & $1437-1718$ & $2260-2210$ \\
\hline 2. & $\begin{array}{l}2 \text { weeks intensity } \\
\text { broad bands-OH }\end{array}$ & $3227-3327$ & $3300-2500$ \\
\hline 3. & C-H stretch & 1437 & $1470-1450$ \\
\hline 4. & C-N medium stretching & 1248 & $1250-1020$ \\
\hline 5. & Medium stretch of $\mathrm{NH}_{2}$ & $1544-1591$ & $1650-1580$ \\
\hline 6. & $\begin{array}{l}\text { Various NH wagging } \\
\text { bonds }\end{array}$ & $419-589$ & $919-665$ \\
\hline 7. & $\begin{array}{l}\text { Various out of CH plan } \\
\text { deformation }\end{array}$ & $992-1044$ & $900-1050$ \\
\hline
\end{tabular}

Table 5: Percentage yield of the formulations

\begin{tabular}{ll}
\hline Formulation & \% Yield \\
\hline F1 & 76.25 \\
F2 & 58.16 \\
F3 & 78.43 \\
F4 & 79.51 \\
F5 & 68.24 \\
F6 & 80.16 \\
F7 & 78.54 \\
F8 & 80.51 \\
F9 & 79.42 \\
\hline
\end{tabular}

Table 6: Percentage entrapment efficiency

\begin{tabular}{ll}
\hline Formulation & Percentage entrapment efficiency \\
\hline F1 & 62.17 \\
F2 & 42.64 \\
F3 & 59.43 \\
F4 & 62.45 \\
F5 & 58.41 \\
F6 & 67.42 \\
F7 & 57.42 \\
F8 & 60.51 \\
F9 & 79.42 \\
\hline
\end{tabular}

Tapped density

Tapped density is used to investigate the packing properties of microcapsules into capsules. The tapped density was measured by employing the conventional tapping method using a $10 \mathrm{~mL}$ measuring cylinder, and the number of tappings was 100 as sufficient to bring a plateau condition. Tapped density was calculated using the following formula:

Tapped Density = Total Weight/Total tapped volume

Hausner's ratio

It is another parameter for measuring flowability of the microspheres. It is calculated using the following formula

$\mathrm{H}=$ Bulk Density/Tapped Density

Compressibility index (Carr's)

It is an indirect measurement of bulk density, size and shape, surface area, moisture content, and cohesiveness of materials since all of them can influence the consolidation index. It is also called a compressibility index. It is denoted by $\mathrm{CI}$ and is calculated using the formula below.

Compressibility index $=(1-\mathrm{Vo} / \mathrm{V}) * 100$

Where, Vo = volume of microspheres before tapping

$\mathrm{V}=$ volume of microspheres after 100 tappings.

Production yield (\%)

The production yield of microspheres of various batches was calculated using the weight of final product after drying with respect to the initial total weight of the drug and polymer used for the preparation of microspheres and percentage production yields were calculated as per the formula:

\section{$\%$ Yield $=$ Actual Yield $/$ Theoretical Yield $\times 100 \%$}

Evaluation of mucoadhesive property

The mucoadhesive property of microspheres was evaluated by an in vitro adhesion testing method known as a wash-off method. Freshly excised pieces of goat stomach mucous were mounted on to glass slides with cotton thread. About 20 microspheres were spread onto each prepared glass slide, and immediately thereafter the slides were hung to USP II tablet disintegration test, when the test apparatus was operated, the sample is subjected to slow up and down movement in simulated gastric fluid ph 6.8 at $37^{\circ} \mathrm{C}$ contained in a 1-L vessel of the apparatus. At an interval of $1 \mathrm{~h}$ up to $8 \mathrm{~h}$, the machine is stopped and number of microspheres still adhering to the mucosal surface was counted.

$\%$ Mucoadhesion $=\frac{\text { Number of microspheres adhered }}{\text { Number of microspheres applied }} \times 100$

In vitro release studies

The in vitro release of flutrimazole microspheres was done with phosphate buffer $\mathrm{pH}$ of 6.8 for $12 \mathrm{~h}$ using dissolution apparatus USP I Basket type at a temperature of $37.0 \pm 0.5^{\circ} \mathrm{C}$. Microsphere equivalent to $10 \mathrm{mg}$ of drug was taken, and it was inserted in the basket wrapping it with a muslin cloth $\left(900 \mathrm{ml}\right.$ phosphate buffer $\mathrm{pH} 6.8$, at $37 \pm 2^{\circ} \mathrm{C}$ and was adjusted to $100 \mathrm{rpm}$ ). The sample was taken every half an hour for $12 \mathrm{~h}$. To maintain the sink condition, the samples withdrawn were replaced with an equal volume of dissolution medium at different time intervals. After suitable dilution, samples were analyzed at UV visible spectrophotometer at $272 \mathrm{~nm}$ [10].

Formulation of the mucoadhesive microsphere-loaded gel

The gels with varying concentrations of Carbopol 934P were prepared by dispersing the required quantity of Carbopol in the required quantity of distilled water with continuous stirring and kept overnight for complete hydration. Further appropriate quantities of triethanolamine were added to the previous polymeric mixture $[11,12]$. The mucoadhesive microsphere of flutrimazole was added to the above polymeric mixture 
with constant stirring. Final $\mathrm{pH}$ of the preparation was adjusted to 4.5 with $0.5 \mathrm{M}$ sodium hydroxide solution. The gel was then further modified by the addition of a varying proportion of HPMCK4M [13]. The composition of all the formulation is given in Table 2.

\section{Characterization of mucoadhesive microsphere gel}

Study of the physical properties

Visual inspection

The organoleptic properties, such as color, texture, consistency, homogeneity, and physical appearance of gel containing microspheres were checked by visual observation.

Determination of $\mathrm{pH}$

Determination of $\mathrm{pH}$ is done using Systronic digital $\mathrm{pH}$ meter 335. $\mathrm{pH}$ meter was calibrated before use using a standard buffer solution.

\section{Viscosity}

The viscosity of the formulated gel is determined by DV-E Brookfield viscometer using spindle no 64

Spreadability

One of the criteria for Emulgel is to meet the ideal quality is that it should possess good spreadability. It is the term expressed to denote the extent of the area to which gel readily spread on application to the

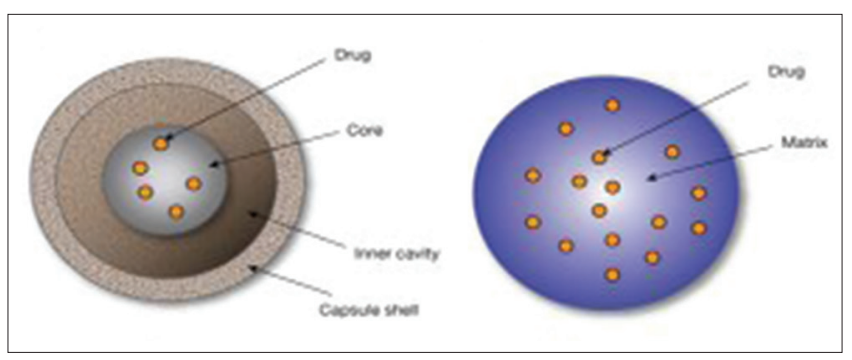

Fig. 1: Schematic diagram illustrating microspheres skin or affected part. The therapeutic efficacy of a formulation also depends on its spreading value. Spreadability is expressed in terms of time in seconds taken by two slides to slip off from emulgel and placed in between the slides under the direction of a certain load. Lesser the time taken for separation of two slides, better the spreadability.

It is calculated using the formula:

$S=M \cdot L / T$

Where,

$\mathrm{M}=$ wt. tied to upper slide $\mathrm{L}=$ length of glass slides. $\mathrm{T}=$ time taken to separate the slides

\section{Extrudability study}

In conducting the test, a closed collapsible tube containing above $20 \mathrm{~g}$ of the gel was pressed firmly at the crimped end, and a clamp was applied to prevent any rollback. The cap was removed and the gel was extruded until the pressure was dissipated (Table 6).

Drug content determination

Drug concentration in emulgel was measured by spectrophotometer. Flutrimazole content in emulgel was measured by dissolving a known quantity of emulgel in solvent (ethanol) by sonication. Absorbance was measured after suitable dilution at $256 \mathrm{~nm}$ in UV/visible spectrophotometer.

\section{In vitro release study}

Franz diffusion cell was used for the drug release studies. Emulgel (200 mg) was applied onto the surface of the cellophane membrane evenly. The cellophane membrane was clamped between the donor and the receptor chamber of the diffusion cell. The receptor chamber was filled with freshly prepared PBS solution to solubilize the drug. The receptor chamber was stirred by a magnetic stirrer. The samples (1.0 ml aliquots) were collected at a suitable time interval. Samples were analyzed for drug content by UV visible spectrophotometer at $256 \mathrm{~nm}$ after appropriate dilutions. Cumulative corrections were made to obtain the total amount of drug release at each time interval. The

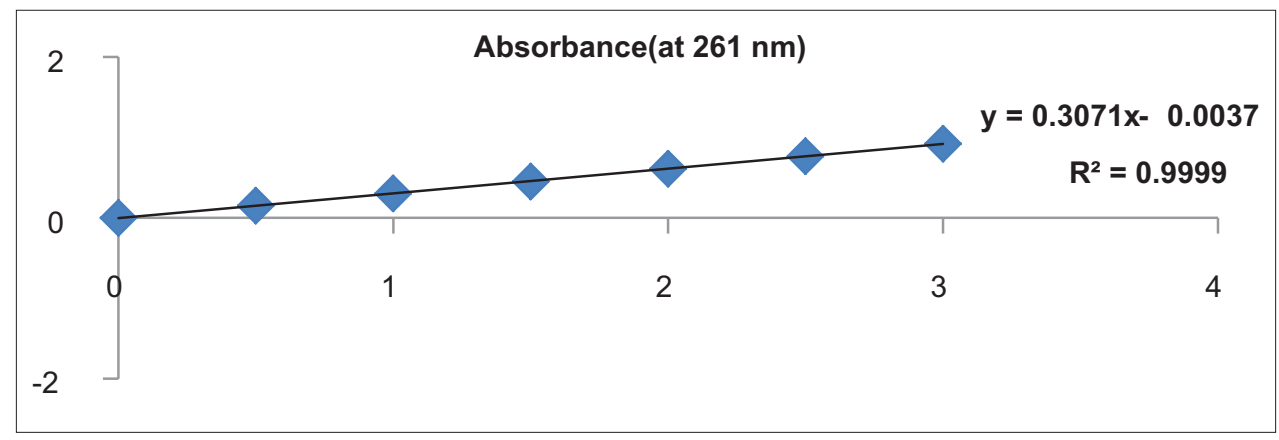

Fig. 2: Standard graph of flutrimazole in simulated gastric fluid pH 6.8

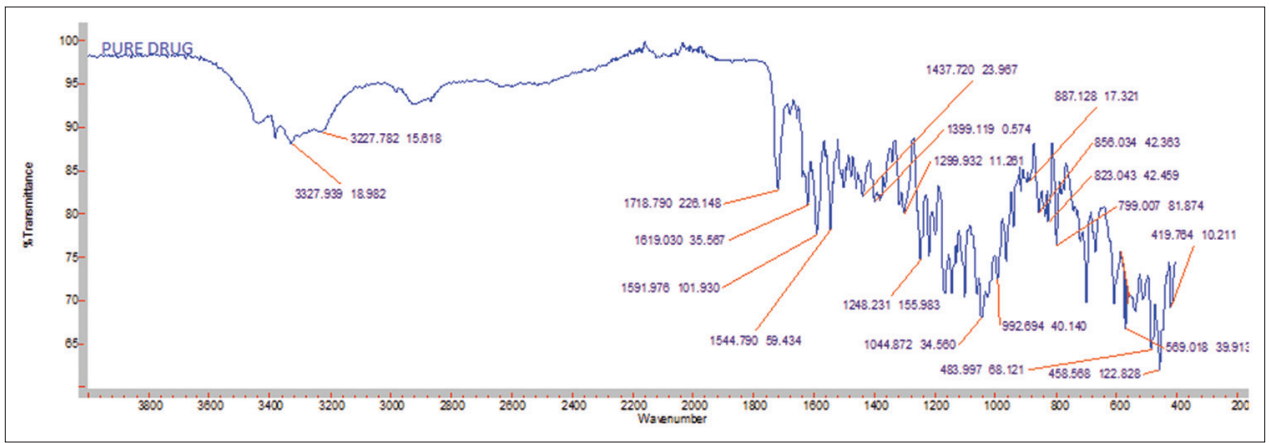

Fig. 3: Fourier transform infrared spectrum of pure drug 
cumulative amount of drug released across the cellophane membrane was determined as a function of time.

\section{Gel strength study}

A sample of $50 \mathrm{~g}$ of microspheres loaded gel was placed in a $100 \mathrm{ml}$ graduated. The apparatus for measuring gel strength (weighing $27 \mathrm{~g}$ ) was allowed to penetrate in the gel. The gel strength, which means the viscosity of the gels was determined by the time (seconds), the apparatus took to sink $5 \mathrm{~cm}$ down through the prepared gel [14]

Accelerated stability studies of emulgel

Stability studies were performed according to the ICH guidelines. The formulations were stored in a hot air oven at $37 \pm 2^{\circ}$ and $45 \pm 2^{\circ}$ for 3 months. The samples were analyzed for its appearance and drug content every 2 weeks by UV-Visible spectrophotometer at $256 \mathrm{~nm}$. Stability study was also carried out by measuring the change in $\mathrm{pH}$ of gel at a regular interval of time.

In vitro drug release kinetics

To determine the release mechanism and kinetics, the results of the in vitro dissolution study of formulated microsphere loaded gel were fitted into various kinetic equations, such as zero-order, first-order,
Higuchi's model, Korsmeyer-Peppas model, and Hixson-Crowell model. Correlation coefficient values $\left(\mathrm{R}^{2}\right)$ were calculated from the linear curves obtained by regression analysis of the plots.

\section{RESULTS AND DISCUSSION}

\section{Determination of $\lambda$}

Stock solution $(1000 \mu \mathrm{g} / \mathrm{ml})$ of flutrimazole was prepared in $0.1 \mathrm{~N} \mathrm{HCl}$. This solution was appropriately diluted with 6.8 phosphate buffer to obtain a concentration of $10 \mu \mathrm{g} / \mathrm{ml}$. The resultant solution was scanned in the range of $200-400 \mathrm{~nm}$ on UV-visible spectrophotometer. The drug exhibited a $\lambda_{\max }$ at $256 \mathrm{~nm}$. A solution of $10 \mu \mathrm{g} / \mathrm{ml}$ of flutrimazole was scanned in the range of $200-400 \mathrm{~nm}$. The drug exhibited a $\lambda_{\max }$ at $256 \mathrm{~nm}$ in 6.8 phosphate buffer and had good reproducibility. Correlation between the concentration and absorbance was found to be near to 0.9999 , with a slope of 0.0245 . Calibration curve spectrums are shown in Table 3 and Fig. 1.

\section{FT-IR incompatibility study of drug and excipient}

The FT-IR spectra of flutrimazole exhibited distinctive peaks at $1718 \mathrm{~cm}^{-1}$ due to $\mathrm{C}=\mathrm{N}$ stretching, $1437 \mathrm{~cm}^{-1}$ due to because of aromatic C-H stretching, and peak at 3227-3327 2 weak intensity broad band's $\mathrm{OH}$ stretching. The spectrum found that there were no interactions of

Table 7: Physical parameters of microspheres loaded topical gels of flutrimazole

\begin{tabular}{|c|c|c|c|c|c|c|}
\hline S. No. & Formulation code & \% Drug content (mg) & Spreadability (g.cm \s) & Viscosity (cps) & $\mathbf{p H}$ & Extrudability study \\
\hline 1. & $\mathrm{~F} 1$ & 92.37 & 11.75 & 210.4 & 6.82 & 95.67 \\
\hline 2. & $\mathrm{~F} 2$ & 91.07 & 11.17 & 217.6 & 6.85 & 96.73 \\
\hline 3. & F3 & 91.48 & 11.25 & 214.56 & 6.87 & 94.55 \\
\hline 4. & $\mathrm{~F} 4$ & 91.88 & 12.55 & 207.55 & 6.88 & 97.62 \\
\hline 5. & F5 & 92.57 & 11.89 & 218.98 & 6.81 & 95.39 \\
\hline 6. & F6 & 93.46 & 12.82 & 221.66 & 6.80 & 95.78 \\
\hline 7. & F7 & 92.55 & 11.79 & 223.54 & 6.82 & 96.43 \\
\hline 9. & F9 & 93.46 & 11.87 & 212.99 & 6.87 & 97.68 \\
\hline
\end{tabular}

Table 8: In vitro release studies

\begin{tabular}{|c|c|c|c|c|c|c|c|c|c|}
\hline Time (h) & $\mathbf{T}_{1}$ & $\mathbf{T}_{2}$ & $\mathbf{T}_{3}$ & $\mathrm{~T}_{4}$ & $\mathbf{T}_{5}$ & $T_{6}$ & $\mathrm{~T}_{7}$ & $\mathbf{T}_{8}$ & $\mathrm{~T}_{9}$ \\
\hline 0 & 0 & 0 & 0 & 0 & 0 & 0 & 0 & 0 & 0 \\
\hline 1 & 24.88 & 21.11 & 18.66 & 15.88 & 27.77 & 22.44 & 18.44 & 17.11 & 25.77 \\
\hline 2 & 31.55 & 31.55 & 25.11 & 24.22 & 36.44 & 32.22 & 29.33 & 26.44 & 35.33 \\
\hline 3 & 42.44 & 39.77 & 35.44 & 32.66 & 43.77 & 40.88 & 39.55 & 37.55 & 43.55 \\
\hline 4 & 53.55 & 47.77 & 40.66 & 39.33 & 54.66 & 48.66 & 45.55 & 46.88 & 54 \\
\hline 5 & 62 & 56.66 & 52 & 47.55 & 64.01 & 57.55 & 57.33 & 55.77 & 63.55 \\
\hline 6 & 74.66 & 62.44 & 57.33 & 55.77 & 75.77 & 63.55 & 65.33 & 63.55 & 75.33 \\
\hline 8 & 89.33 & 75.33 & 69.11 & 69.55 & 90 & 76.55 & 77.56 & 75.77 & 89.77 \\
\hline 9 & 92.66 & 84.66 & 75.33 & 77.55 & 92.22 & 85.55 & 81.55 & 79.77 & 92.66 \\
\hline 10 & 85.55 & 90.66 & 82.66 & 85.55 & 84.88 & 91.33 & 83.33 & 82.44 & 85.11 \\
\hline 11 & 80.22 & 84.22 & 90.66 & 90.66 & 79.55 & 85.77 & 89.55 & 86.88 & 80.66 \\
\hline 12 & 78.88 & 80.88 & 89.55 & 94.66 & 77.55 & 81.11 & 87.55 & 90.66 & 78 \\
\hline
\end{tabular}

Table 9: In vitro cumulative percentage drug release profile for flutrimazole microspheres loaded gels

\begin{tabular}{|c|c|c|c|c|c|c|c|c|c|}
\hline Time (h) & F1 & F2 & F3 & F4 & F5 & F6 & F7 & F8 & F9 \\
\hline 0.5 & 9.77 & 12.14 & 6.12 & 14.21 & 8.11 & 5.12 & 2.11 & 9.21 & 18.51 \\
\hline 1 & 17.51 & 23.16 & 15.45 & 21.55 & 17.5 & 10.22 & 8.15 & 21.8 & 22.15 \\
\hline 2 & 23.4 & 28.77 & 20.47 & 22.47 & 22.85 & 18.21 & 15.21 & 29.21 & 28.55 \\
\hline 3 & 28.14 & 32.47 & 25.44 & 35.11 & 28.14 & 28.77 & 29.54 & 35.11 & 32.14 \\
\hline 4 & 32.11 & 38.64 & 30.14 & 40.94 & 33.14 & 34.57 & 33.47 & 39.45 & 38.74 \\
\hline 5 & 36.97 & 42.97 & 35.79 & 45.71 & 36.47 & 36.11 & 37.64 & 48.21 & 42.44 \\
\hline 6 & 41.97 & 46.12 & 40.78 & 55.87 & 42.64 & 39.14 & 42.55 & 53.77 & 48.71 \\
\hline 8 & 52.77 & 52.74 & 60.22 & 61.47 & 52.77 & 46.78 & 53.11 & 65.77 & 66.54 \\
\hline 9 & 55.94 & 58.44 & 63.48 & 69.14 & 56.52 & 49.14 & 56.47 & 72.64 & 71.24 \\
\hline 10 & 61.87 & 75.32 & 69.47 & 73.41 & 62.99 & 59.14 & 62.44 & 89.54 & 82.14 \\
\hline 11 & 69.77 & 85.11 & 73.44 & 79.41 & 68.14 & 69.14 & 68.21 & 93.11 & 86.14 \\
\hline 12 & 85.22 & 93.47 & 88.14 & 88.37 & 88.17 & 85.22 & 88.54 & 97.45 & 94.14 \\
\hline
\end{tabular}



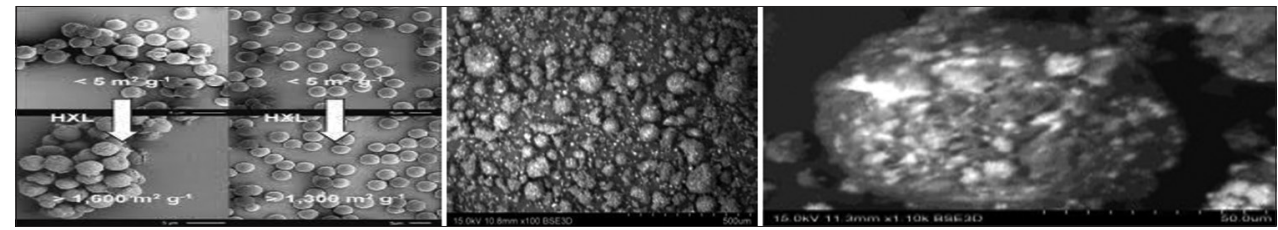

Fig. 4: Scanning electron microscopy

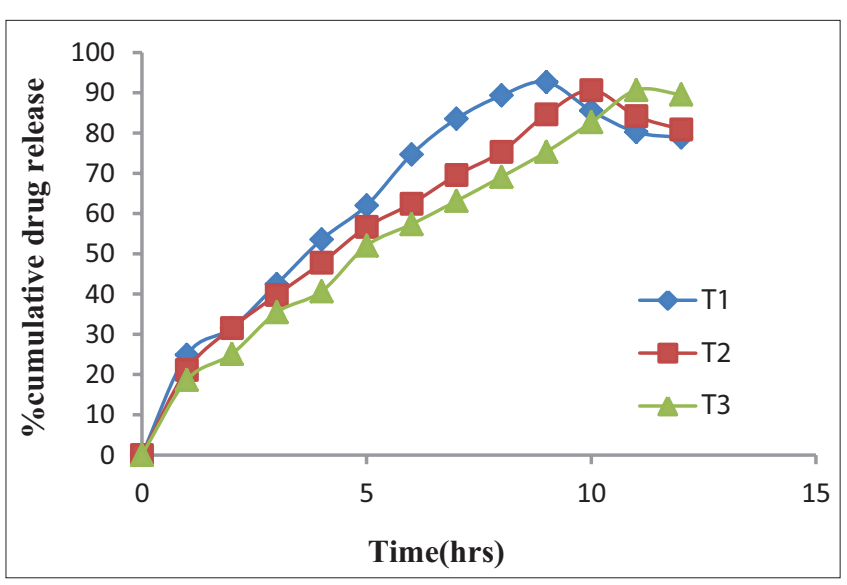

Fig. 5: Dissolution profile of T1, T2, and T3 formulations

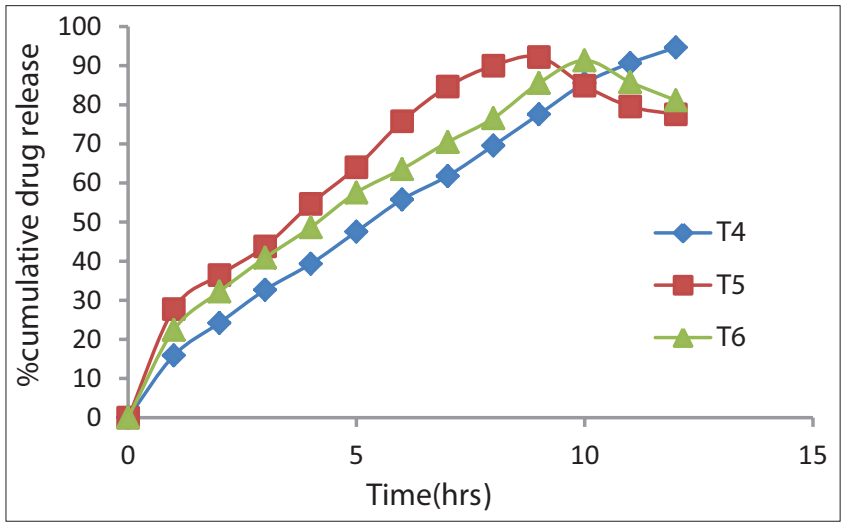

Fig. 6: Dissolution profile of T4, T5, and T6 formulations

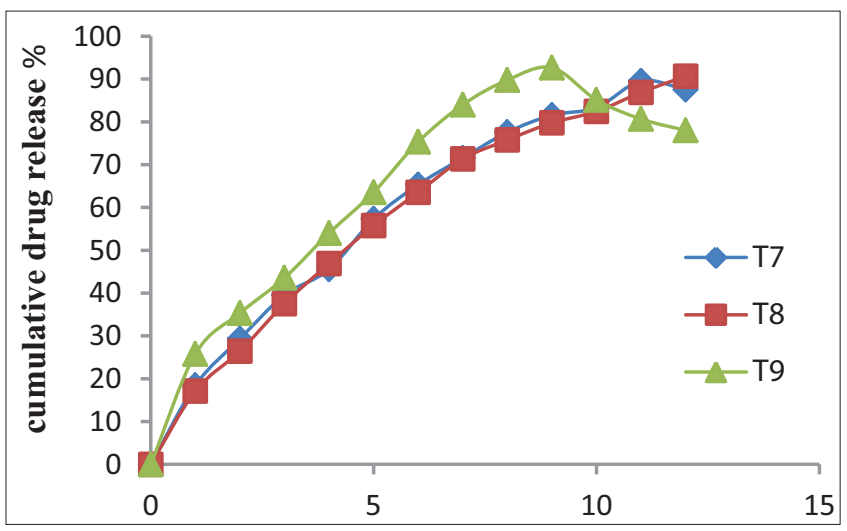

Fig. 7: Dissolution profile of T7, T8, and T9 formulations

the drug with excipients. Hence, it indicates no change in the chemical integrity of the drug. FT-IR spectrums are shown in Fig. 2 and data in Table 4.

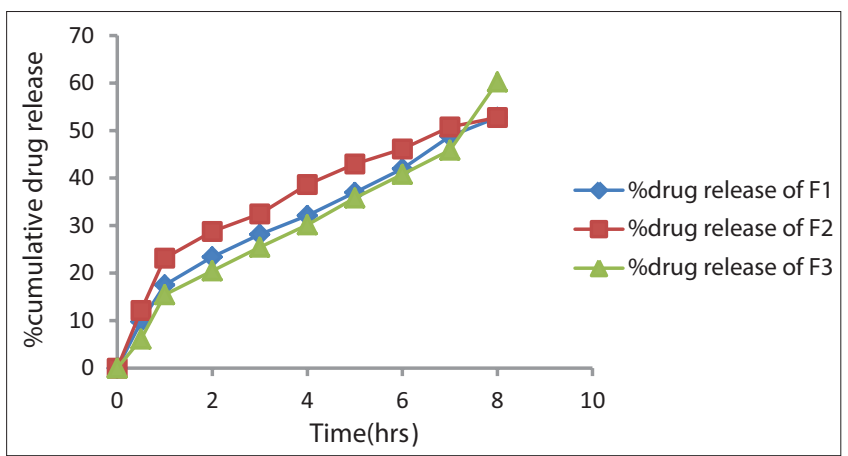

Fig. 8: Dissolution profile of F1, F2, and F3 formulations

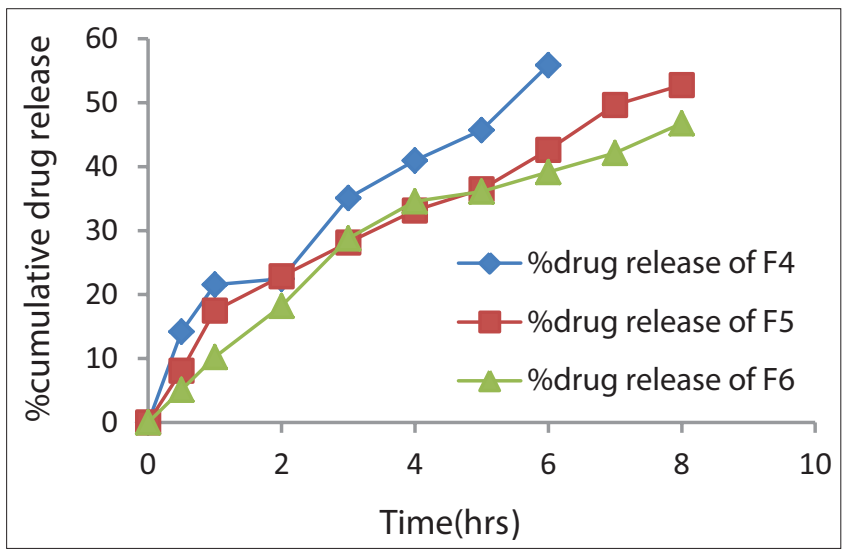

Fig. 9: Dissolution profile of F4, F5, and F6 formulations

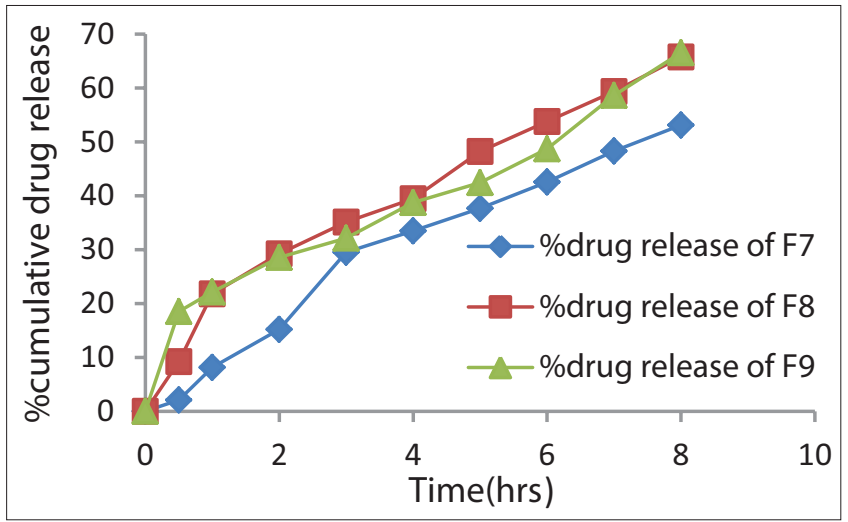

Fig. 10: Dissolution profile of F7, F8, and F9 formulations

Drug and excipient compatibility studies

Percentage yield

It was observed that as the polymer ratio in the formulation increases, the product yield also increases. The low percentage yield in some formulations may be due to blocking of needle and wastage of the drug-polymer solution, adhesion of polymer solution to the magnetic 
bead and microspheres lost during the washing process. The percentage yield was found to be in the range of $76-82 \%$ for microspheres containing HPMC polymer. Results are shown in Table 5.

\section{Evaluation of the microspheres}

\section{Surface morphology and particle size analysis}

The average particle size of all the formulations was in the range of 30-120 $\mu \mathrm{m}$ and particle size was increased with increase in the concentration of the polymer. The increase in viscosity of polymer solution with an increase in polymer concentration produced larger

Table 10: Release kinetics data for optimized formulation

\begin{tabular}{llllll}
\hline $\begin{array}{l}\text { Cumulative (\%) } \\
\text { release Q }\end{array}$ & $\begin{array}{l}\text { Time } \\
\text { (T) }\end{array}$ & $\begin{array}{l}\text { Root } \\
\text { (T) }\end{array}$ & $\begin{array}{l}\text { Log (\%) } \\
\text { release }\end{array}$ & $\begin{array}{l}\text { Log } \\
\text { (T) }\end{array}$ & $\begin{array}{l}\text { Log (\%) } \\
\text { remain }\end{array}$ \\
\hline 0 & 0 & 0 & & & 2.000 \\
9.21 & 30 & 5.477 & 0.964 & 1.477 & 1.958 \\
21.8 & 60 & 7.746 & 1.338 & 1.778 & 1.893 \\
29.21 & 120 & 10.954 & 1.466 & 2.079 & 1.850 \\
35.11 & 240 & 15.492 & 1.545 & 2.380 & 1.812 \\
39.45 & 360 & 18.974 & 1.596 & 2.556 & 1.782 \\
48.21 & 480 & 21.909 & 1.683 & 2.681 & 1.714 \\
53.77 & 600 & 24.495 & 1.731 & 2.778 & 1.665 \\
59.34 & 720 & 26.833 & 1.773 & 2.857 & 1.609 \\
65.77 & 780 & 27.928 & 1.818 & 2.892 & 1.534 \\
72.64 & 840 & 28.983 & 1.861 & 2.924 & 1.437 \\
89.54 & 900 & 30.000 & 1.952 & 2.954 & 1.020 \\
93.11 & 960 & 30.984 & 1.969 & 2.982 & 0.838 \\
97.45 & 1020 & 31.937 & 1.989 & 3.009 & 0.407 \\
\hline
\end{tabular}

Table 11: Accelerated stability study of optimized microspheres loaded gel formulation $\mathrm{F} 8$ at $25^{\circ} \mathrm{C}$

\begin{tabular}{llll}
\hline $\begin{array}{l}\text { Storage temperature } \\
{ }^{\circ} \mathbf{C} \mathbf{2 5} \pm \mathbf{2}\end{array}$ & \multicolumn{3}{l}{ Period of studies in month } \\
\cline { 2 - 4 } & $\mathbf{1}$ month & 2 month & 3 month \\
\hline Appearance & Good & Good & Good \\
Drug content & $95.86 \pm 0.05$ & $96.29 \pm 0.11$ & $96.19 \pm 0.05$ \\
pH & $6.77 \pm 0.06$ & $6.78 \pm 0.018$ & $6.80 \pm 0.028$ \\
\hline
\end{tabular}

Table 12: Accelerated stability study of optimized microspheres loaded gel formulation $\mathrm{F} 5$ at $45^{\circ} \mathrm{C}$

\begin{tabular}{llll}
\hline Storage temperature & \multicolumn{3}{l}{ Period of studies in month } \\
\cline { 2 - 4 }${ }^{\circ} \mathbf{C} \mathbf{2 5} \pm \mathbf{2}$ & $\mathbf{1}$ month & 2 month & 3 month \\
\hline Appearance & Good & Good & Good \\
Drug content & $97.96 \pm 0.01$ & $97.89 \pm 0.03$ & $97.43 \pm 0.02$ \\
pH & $6.79 \pm 0.09$ & $6.79 \pm 0.014$ & $6.80 \pm 0.013$ \\
\hline
\end{tabular}

particles in higher polymer formulations. Microspheres are shown in Fig. 3. The microspheres obtained under the conditions were found to be spherical and without aggregation, and median size ranged from 8 to $19 \mu \mathrm{m}$.

\section{Encapsulation efficiency}

The encapsulation efficiency ranged from 62.17 to $79.42 \%$. The encapsulation efficiency increased as the concentration of polymer (encapsulating material) was increased, and data are shown in Table 6.

In vitro drug release study

In vitro release profile of flutrimazole-loaded microspheres in phosphate buffer with $\mathrm{pH}$ of 6.8. Here, sustained release of drug was observed from the formulation in phosphate buffer ( $\mathrm{pH}$ 6.8) for a duration of 12 h. About 58.09-75.89\% of drug release was achieved in $<7 \mathrm{~h}$ from the microspheres. The improvement of the dissolution rate of the drug from the microspheres can be also due to their small size and the cross-linking of polymer and drug that lead to the uniform dispersion of the drug into the polymeric network.

Scanning electron microscopy

The microspheres prepared by solvent evaporation method have a good spherical shape with a smooth surface in its morphology, and the particles were distributed uniformly without forming any clumps.

Characterization of drug-loaded emulgel

Physical appearance

The prepared flutrimazole emulgel formulations were white to slightly yellowish, viscous creamy preparation with a smooth and homogeneous appearance.

$\mathrm{pH}$

The $\mathrm{pH}$ values of all formulations were found in the range of 6.50-6.80. Hence, all the formulations are satisfactorily complying with $\mathrm{pH}$ values needed for topical application and $\mathrm{pH}$ of the skin.

Spreadability

The observations for spreadability of all formulations are shown in Table 7. The spreadability of the formulation depends on its viscosity. The greater the viscosity, the longer will be the time taken for spreading on the skin. The values of spreadability denote that the gel is easily spreadable by the small amount of force. The spreadability of formulation F3 was found to be less as compared to F8 formulations; this indicates high viscosity of Carbopol gel rigid to spread on the skin. Gel strength is important because strong gels will support a much higher pressure than weak gels before they are washed out of the targeted site. The formulations exhibited moderate gel strength, as shown in Table 6

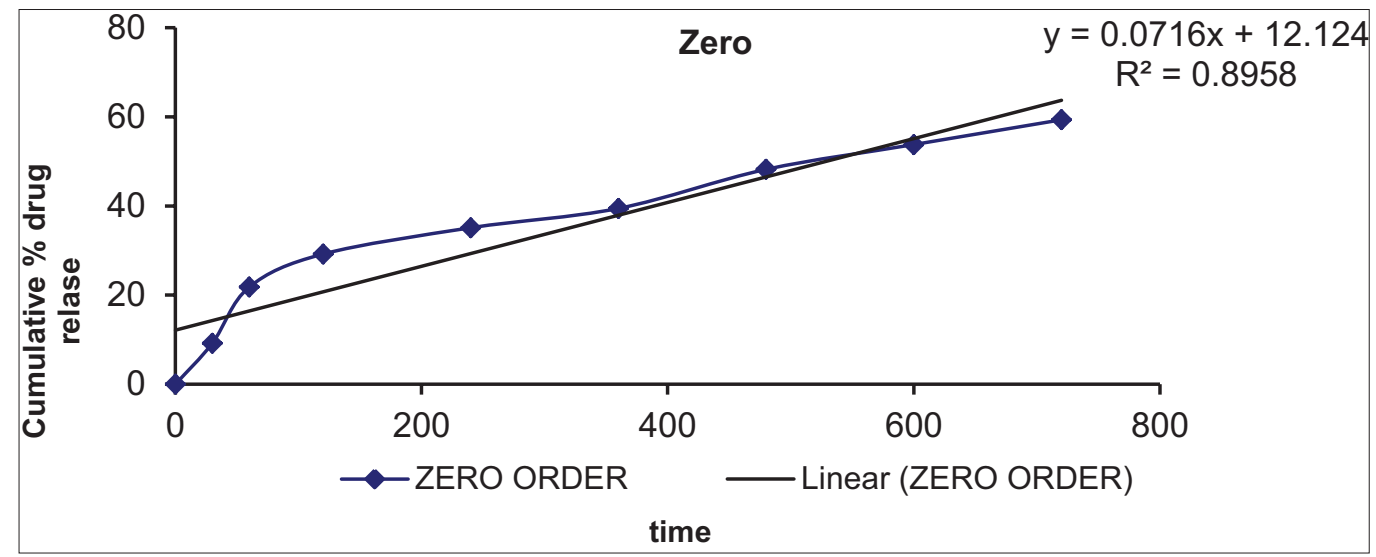

Fig. 11: Zero-order release kinetics graph 
Viscosity

The viscosity of the gels was determined using DV-E Brookfield viscometer using spindle no 64. The viscosity was found to be 221.66223.66 cps, of F6, F7, and F8, respectively. The increase in viscosity of the formulations was directly proportional to the polymer concentration.

Extrudability

The observations for extrudability of all formulations are shown in Table 7. F8 formulation shows highest extrudability when compared with other formulations.

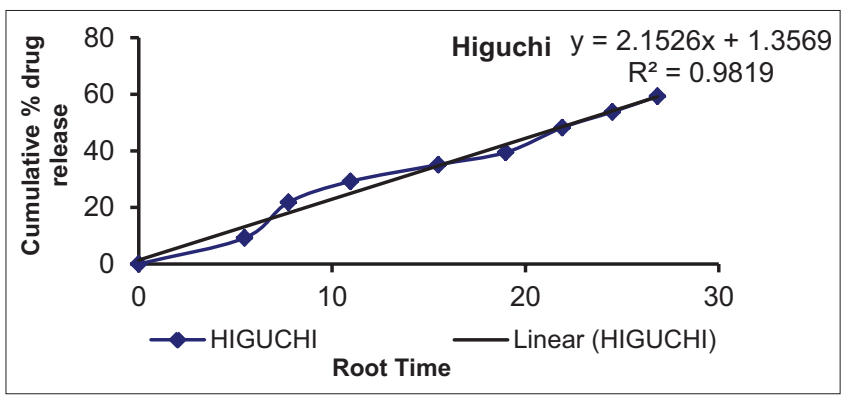

Fig. 12: Higuchi release kinetics graph

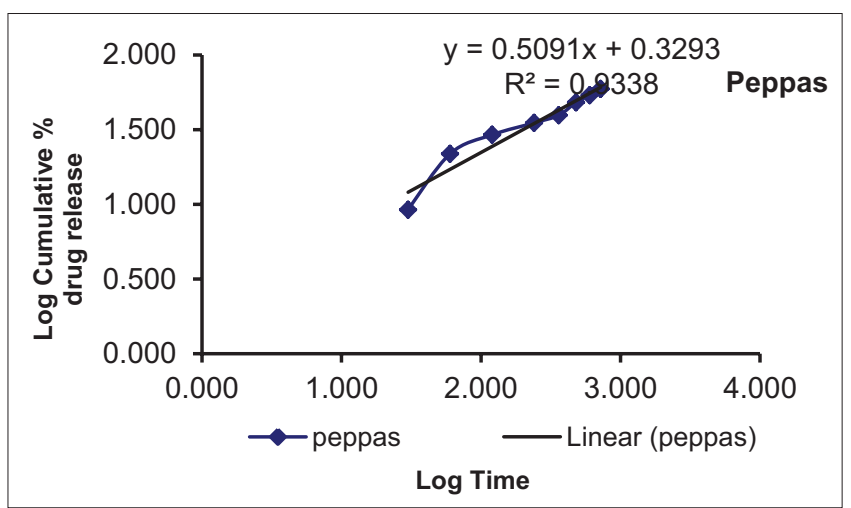

Fig. 13: Kars mayer peppas graph

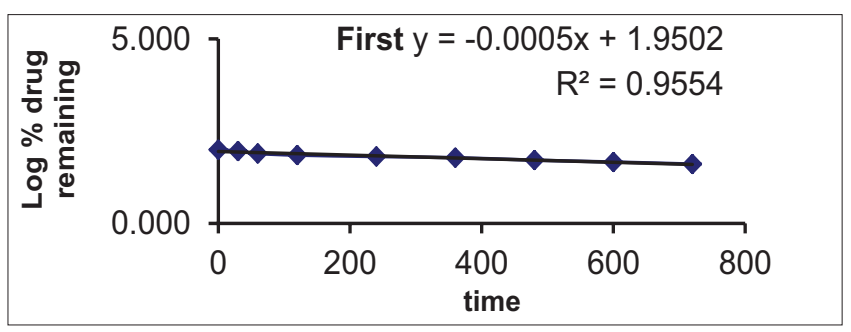

Fig. 14: First-order release kinetics graph
Drug content determination

$1 \mathrm{~g}$ of the prepared microspheres loaded topical gels was mixed with $100 \mathrm{ml}$ of a suitable solvent (ethanol). Aliquots of different concentration were prepared by suitable dilution after sonication and filtering the stock solution, and absorbance was measured. Drug content was calculated using the equation, which was obtained by linear regression analysis of the calibration curve. The drug content of microspheres loaded topical gels of flutrimazole formulations is given in Table 7.

\section{In vitro drug release}

Diffusion studies of all the formulations were carried out using Franz diffusion apparatus. The diffusion studies were conducted using diffusion media, $\mathrm{pH}$ 6.8. This shows that more sustained release was observed with the increase in the percentage of polymers. As the polymer to drug ratio was increased, the extent of drug release decreased. The in vitro release profiles of flutrimazole from its various microspheres loaded topical gel formulations are represented in Fig. 5. It was observed that all the formulation had become liquefied and diluted at the end of the experiments, indicating water diffusion through the membrane. In general, it can be observed from figures that the better release of the drug from all emulgel formulation. The release of the drugs from its emulgel formulation can be ranked in the following descending order: F8 $>$ F9 $>$ F2 $>$ F4 $>$ F5 $>$ F7 $>$ F3 $>$ F1, where the amounts of the drug release of the drug released after $24 \mathrm{~h}$ were $97.45 \%, 94.14 \%, 93.47 \%, 88.37 \%$, $88.17 \%, 85.22 \%, 88.11 \%$, and 85.22 , respectively. Thus, the higher drug release was observed with formulation F8. The lower drug release of formulations may be attributed to the high polymer concentration in the former. With an increase in the polymer concentration, the micelles formed are closely packed on gelation thus resisting the drug release to the external environment [15].

\section{In vitro release studies}

\section{In vitro drug release kinetics}

For understanding the mechanism of drug release and release rate kinetics of the drug from dosage form, the in vitro drug diffusion data obtained were fitted to various mathematical models such as zeroorder, first-order, Higuchi matrix, and Korsmeyer-Peppas model. The coefficient of determination $\left(\mathrm{R}^{2}\right)$ was used as an indicator of the best fitting for each of the models considered. The kinetic data analysis of all the formulations reached higher coefficient of determination with the Higuchi release kinetics model $\left(\mathrm{R}^{2}=0.9819-0.996\right)$ whereas release exponent value (n) ranged from 0.496 to 0.753 . From the coefficient of determination and release exponent values, it can be suggested that the mechanism of drug release follows Higuchi release kinetics model along with non-Fickian diffusion mechanism which leads to the conclusion that a release mechanism of drug followed the combination of diffusion and spheres erosion and values, as shown in Table 10.

\section{Stability studies}

A stability study of the optimized formulation was done for appearance, $\mathrm{pH}$, and viscosity for up to 90 days at a time interval of 30 days. The

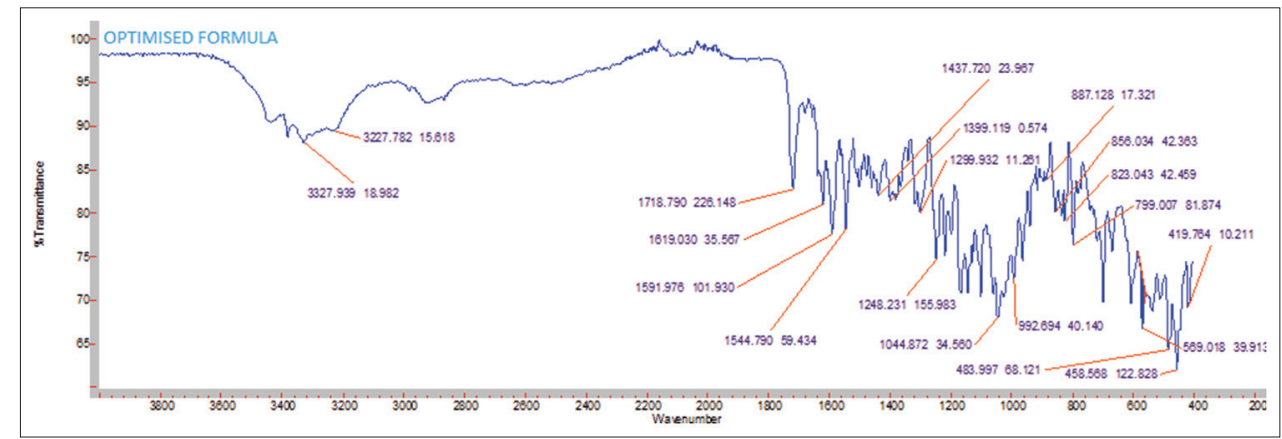

Fig. 15: Fourier transform infrared spectrum of optimized formulation 
Table 13: Pre formulation parameters

\begin{tabular}{|c|c|c|c|c|c|c|c|}
\hline S. No. & $\begin{array}{l}\text { Formulation } \\
\text { code }\end{array}$ & $\begin{array}{l}\text { Mean particle } \\
\text { size }(\mu \mathrm{m})\end{array}$ & $\begin{array}{l}\text { Bulk density } \\
\mathrm{g} / \mathrm{cm}^{3}\end{array}$ & $\begin{array}{l}\text { Tapped } \\
\text { density }\end{array}$ & $\begin{array}{l}\text { Hausner's } \\
\text { ratio }\end{array}$ & $\begin{array}{l}\text { Carr's } \\
\text { index }\end{array}$ & $\begin{array}{l}\text { Angle of } \\
\text { repose }\end{array}$ \\
\hline 1. & F1 & 650 & $0.49 \pm 0.04$ & $0.54 \pm 0.04$ & $16.21 \pm 0.06$ & $0.86 \pm 0.06$ & 25.11 \\
\hline 2. & $\mathrm{~F} 2$ & 670 & $0.52 \pm 0.09$ & $0.52 \pm 0.04$ & $16.87 \pm 0.05$ & $0.98 \pm 0.05$ & 25.67 \\
\hline 3. & F3 & 720 & $0.50 \pm 0.05$ & $0.58 \pm 0.05$ & $17.11 \pm 0.01$ & $0.64 \pm 0.03$ & 25.54 \\
\hline 4. & $\mathrm{~F} 4$ & 690 & $0.51 \pm 0.06$ & $0.54 \pm 0.07$ & $17.67 \pm 0.08$ & $1.12 \pm 0.04$ & 25.43 \\
\hline 5. & F5 & 780 & $0.52 \pm 0.03$ & $0.57 \pm 0.03$ & $16.92 \pm 0.04$ & $6.8 \pm 0.08$ & 27.34 \\
\hline 6. & F6 & 770 & $0.53 \pm 0.04$ & $0.56 \pm 0.06$ & $17.65 \pm 0.09$ & $1.06 \pm 0.09$ & 26.22 \\
\hline 8. & F8 & 690 & $0.51 \pm 0.09$ & $0.54 \pm 0.04$ & $16.67 \pm 0.05$ & $0.87 \pm 0.05$ & 26.67 \\
\hline 9. & F9 & 700 & $0.53 \pm 0.05$ & $0.55 \pm 0.05$ & $17.73 \pm 0.01$ & $0.67 \pm 0.03$ & 28.54 \\
\hline
\end{tabular}

Mean \pm standard deviation $(\mathrm{n}=3)$

formulation did not show much variation in any of the parameters. The results obtained are tabulated in Tables 7 and 8 . From these results, it was concluded that formulation F8 was stable throughout the period. These data reported in Table 12.

\section{Drug and excipient compatibility studies of optimized formulation}

\section{CONCLUSION}

In the present work, bioadhesive microspheres of flutrimazole using different polymers were formulated to deliver flutrimazole through topical route. Increase in the polymer concentration led to an increase in percentage yield, percentage drug entrapment efficiency, and particle size. The in vitro drug release decreased with an increase in the polymer. Analysis of drug release mechanism showed that the drug release from the formulations followed diffusion, and the best fit model was found to be Higuchi release kinetics. FT-IR studies were carried out to find out the possible interaction between the selected drugs and polymer. FTIR studies revealed that there was no interaction between the selected drugs and polymer. Among the different batches, formulation F8 was selected as the ideal formulations, after considering their mean particle size, free-flowing nature, better drug loading capacity, and in vitro drug release. The percentage of drug release microspheres was found to be $97.45 \%$.

\section{ACKNOWLEDGMENT}

Authors wish to express their sincere thanks to the management of Gurunank Institute of Technical Sciences, Hyderabad, for providing research facilities for completion of project work.

\section{AUTHORS' CONTRIBUTIONS}

Both M. Radhika Reddy and Soumyastutipatnaik have carried out experiments, analyzed results, and typing the manuscript.

\section{CONFLICTS OF INTEREST}

The authors declared that there are no conflicts of interest.

\section{REFERENCES}

1. Rang HP, Dale MM, Ritter JM, Flower RJ. Anti-inflammatory and immunosuppressant drugs. In: Rang and Dale's Pharmacology. $6^{\text {th }}$ ed., Ch. 14. Edinburgh: Elsevier Publications; 2008. p. 226-45.

2. Chien YW. Concepts and system design for rate-controlled drug delivery. Novel Drug Delivery System. $2^{\text {nd }}$ ed., Ch. 1. New York: Marcel Dekker, Inc.; 1992. p. 1-42.

3. Das S, Das MK. Synthesis and characterisation of thiolated jackfruit seed starch as a colonic drug delivery carrier. Int J Appl Pharm 2019;11:53-62

4. Rang HP, Dale MM, Ritter JM, Flower RJ. Anti-inflammatory and immunosuppressant drugs. In: Rang and Dale's Pharmacology. $6^{\text {th }}$ ed., Ch. 14. Edinburgh: Elsevier Publications; 2008. p. 226-45.

5. Chen X, Peng L, Gao J, Novel topical drug delivery systems and their potential use in scars treatment. Asian J Pharm Sci 2012;7:155-67.
6. Sigh RP, Parpani S, Narke R, Chavan R. Emulgel: A recent approach for topical drug delivery system. Asian J Pharm Res Dev 2014;2:13-5.

7. Chien YW. Rate-controlled drug delivery systems. Indian J Pharm Sci 1988:4:63-5.

8. Gurulningappa S, Hallur MS. Anti-inflammatory assays of extracts of medicinal plants. Indian J Pharm Sci 2002;64:498-500.

9. Singh M, Mittal V. Formulation and evaluation of herbal gel containing ethanolic extract of Ipomoea fistulosa. Int J Sci Res 2014;3:25-9.

10. Dixit G, Misal G, Gulkari V, Upadhye K. Formulation and evaluation of polyherbal gel for anti-inflammatory activity. Int J Pharm Sci Res 2013;4:1186-91

11. Gohel MC, Parikh RK, Amin AF, Surati AK. Preparation and formulation optimization of sugar crosslinking gelatin microspheres of diclofenac sodium. Indian J Pharm Sci 2005;67:575-81.

12. Rouge N, Buri P, Doelker E. Drug absorption sites in the gastrointestinal tract and dosage forms for site specific delivery. Int $\mathrm{J}$ Pharm 1996:136:117-39.

13. Lee TW, Robinson JR. Controlled release drug-delivery systems. In: Remington's Pharmaceutical Sciences. $20^{\text {th }}$ ed., Ch. 47. Pennsylvania: Mack Publishing Company; 2000. p. 903-29.

14. Cevc G, Vierl U. Nanotechnology and the transdermal route: A state of the art review and critical appraisal. J Control Release 2010;141:277-99.

15. Bhandke SE. Formulation and development of repaglinide microparticles by ionotropic gelation techniques. Indian J Pharm Educ Res 2006;.

16. Desai S, Vidyasagar G, Shah V, Desai D. Preparation and in-vitro characterization of mucoadhesive microspheres of midazolam: Nose to brain administration. Asian J Pharm Clin Res 2011;4:100-2. Gavini E, Hegge AB, Rassu G, Sanna V, Testa C, Pirisino $\mathrm{G}$, et al. Nasal administration of carbamazepine using chitosan microspheres: In vitro/in vivo studies. Int J Pharm 2006;307:9-15.

17. Alexander A, Dwivedi S, Ajazuddin, Giri TK, Saraf S, Saraf S, et al. Approaches for breaking the barriers of drug permeation through transdermal drug delivery. J Control Release 2012;164:26-40.

18. Doddayya H, Srishailgouda SP, Reddy BT, Kumar P, Rajagopal HU, Shree MV. Formulation and evaluation of brain-targeted nasal selegiline hydrochloride microspheres. Int J Pharm Biomed Res 2014;5:61-8.

19. Kumar JR, Muralidharan S, Ramasamy S. Microsponges enriched Gel (Megs): A novel strategy for opthalmic drug delivery system containing ketotifen. J Pharm Res 2013;5:97-102.

20. Chadawar V, Shaji J. Microsponge delivery system. Curr Drug Deliv 2007:4:123-9

21. Rashmi M. Topical Gel: A Review; 2008. Available from: http://www. pharmainfo.com.

22. Okur NU, Apaydın S, Karabay Yavaşoğlu NÜ, Yavaşoğlu A, Karasulu HY. Evaluation of skin permeation and anti-inflammatory and analgesic effects of new naproxen microemulsion formulations. Int $\mathrm{J}$ Pharm 2011;416:136-44.

23. Sharma S. Topical preparations are used for the localized effects at the site of their application by virtue of drug penetration into the underlying layers of skin or mucous membranes. Pharm Rev 2008;6:1-10.

24. Zhao L, Wang Y, Zhai Y, Wang Z, Liu J, Zhai G, et al. Ropivacaine loaded microemulsion and microemulsion-based gel for transdermal delivery: Preparation, optimization, and evaluation. Int J Pharm 2014;477:47-56. Elmowafy M, et al. ??? Beni-Suef Univ J Basic Appl Sci 2017;6:184-91.

25. Kasting GB. Kinetics of finite dose absorption through skin 1 . Vanillylnonanamide. J Pharm Sci 2001;90:202-12.

26. El-Hadidy GN, Ibrahim HK, Mohamed MI, El-Milligi MF. Microemulsions as vehicles for topical administration of voriconazole: 
Formulation and in vitro evaluation. Drug Dev Ind Pharm 2012;38:64-72.

27. Jyothi D, Koland M. Formulation and evaluation of an herbal antiinflammatory gel containing Trigonella foenum-greacum seed extract. Int J Pharm Pharm Sci 2016;8:41-4.

28. Bhaskar K, Anbu J, Ravichandiran V, Venkateswarlu V, Rao YM. Lipid nanoparticles for transdermal delivery of flurbiprofen: Formulation, in vitro, ex vivo and in vivo studies. Lipids Health Dis 2009;8:6.

29. Mohamed MI. Topical emulsion gel composition comprising diclofenac sodium. Am Assoc Pharm Sci 2004;6:1-7.

30. Zuckerman JM. Macrolides and ketolides:Azithromycin, clarithromycin, telithromycin. Infect Dis Clin North Am 2004;18:621-49, 11.

31. Murthy SN, Hiremath SR. Physical and chemical permeation enhancers in transdermal delivery of terbutaline sulphate. AAPS PharmSciTech
2001;2:E-TN1.

32. Mohamed MI. Optimization of chlorphenesin emulgel formulation. AAPS J 2004;6:e26.

33. Ansel HC, Allen LV Jr., Popovich NG. Pharmaceutical Dosage Forms and Drug Delivery Systems. $7^{\text {th }}$ ed. New York: Lippincott Williams and Wilkins; 1999.

34. Bonacucina G, Cespi M, Palmieri GF. Characterization and stability of emulsion gels based on acrylamide/sodium acryloyldimethyl taurate copolymer. AAPS PharmSciTech 2009;10:368-75.

35. Kumar L, Verma R. In vitro evaluation of topical gelprepared using natural polymer. Int J Drug Deliv 2010;2:58-63.

36. Gupta A, Mishra AK, Singh AK, Gupta V, Bansal P. Formulation and evaluation of topical gel of diclofenac sodiumusing different polymers. Drug Invent Today 2010;2:250-25 